\title{
Editorial
}

\section{Welfare in Latin America and the Nordic countries - editorial notes}

by

Morten Tønnessen

Professor of Philosophy

Department of Social Studies, University of Stavanger

E-mail: morten.tonnessen@uis.no

Sarah Catherine Patricia Duff Hean

Professor

Department of Social Studies, University of Stavanger

E-mail: sarah.c.hean@uis.no

Siv Oltedal

Professor

Department of Social Studies, University of Stavanger

E-mail: siv.oltedal@uis.no

Angela Peña

Professor

Department of Sociology, University of Havana

E-mail: angelap@ffh.uh.cu

DOI: https://doi.org/10.31265/jcsw.v14.i1.230

\section{(c) (1) (2)}

This work is licensed under a Creative Commons Attribution-ShareAlike 4.0 International License. 
There is a lack of research into social worker perspectives in a Latin American context and a comparison of these with European social work practices that currently predominate in the literature. In response to this shortfall, a Nordic-Latin American research seminar on welfare issues was held at the University of Havana's Department of Sociology in January 2018. This special issue, 'Welfare in Latin America and the Nordic countries', was conceived during this seminar, as was the NORPART project 'Cuban and Nordic welfare' (2019-2023), funded by the Norwegian Partnership Programme for Global Academic Cooperation. The guest editors (the authors of this editorial) participated in the events.

\section{Overview of the special issue}

Although our starting point was a Norwegian-Cuban connection, the special issue addresses Latin America and the Nordic countries more broadly, since there are several issues related to welfare that transfer across these wider international regions. The special issue involves contributions from academics in Chile, Cuba, Norway and Sweden, with in-depth studies on Brazil (Heitmann), Chile (Ellingsen et al., Jensen et al.; Oltedal and Nygren), Cuba (Oltedal et al.), Mexico (Ursin) and Norway (Ellingsen et al.; Oltedal and Nygren, Oltedal et al.), with additional coverage of England and Lithuania (Oltedal and Nygren).

A variety of theoretical lenses have been applied. For example, Jensen et al. explore the concept of child visibility in the social work practices of Chilean social workers, whereas Ursin draws on Dionysian, Apollonian and Athenian views of childhood. A variety of methodological approaches were also used, with qualitative methodologies predominating. Vignette driven focus groups with social workers to compare and contrast social work practices were particularly popular (Ellingsen et al., Oltedal and Nygren and Oltedal et al.). Q methodology was used by Jensen et al. to explore to what extent groups of social workers share perspectives of the child in their practice.

Three articles (Ellingsen et al., Oltedal et al. and Oltedal and Nygren) arise from discrete projects within the remit of the NORFACE funded project: Family Complexity and Social Work (FACSK), a comparative study of family-based welfare work in different welfare regimes (2015-2017). The aim of these projects was to explore how social workers who work with families across a European context (England, Lithuania 
and Norway) and Latin America (Chile and Cuba) understand notions of family, and how they describe their practices with families in child welfare and mental health service areas.

All but one of the articles of the special issue (Tønnessen) explore the front-line social worker perspective in different environments, and of these three are concerned with child welfare. While Jensen et al. and Ellingsen et al. focus on social workers working within child protection services in Chile and Norway, Ursin investigates the context of Mexican child care institutions. They explore social workers perceptions of childhood and notions of responsibility with regard to family life. Jensen et al. suggest that some Chilean social workers see children as capable and unique, and hence able to fully participate in welfare service delivery. Ellingsen et al. suggest that this view is more common among Norwegian social workers, especially if compared to another view held by other Chilean social workers who see the child as being at risk or vulnerable. Many Chilean social workers favour an external view of the child's needs, rather than that of the children themselves (Ellingsen et al., Jensen et al.). Mexican social workers appear more in tune with Norwegian professionals in this regard, with regulations in Mexican institutions demonstrating a blend of strict control of behaviour and a child-centred policy offering opportunities to the child to participate as a responsible citizen in society. Their vision of the child is one of a national citizen prepared to be a sanitary, responsible worker, regulating his or her own physical experiences and sexuality.

Overall, papers collected in this issue have highlighted some important points for consideration and future action among social workers and social work researchers. This is described in the following two sections.

\section{Social work practice must be seen in light of social change}

Over the last few decades, Latin American and European countries have undergone considerable, and in some cases unprecedented, social change that has had a considerable impact on the conditions of doing social work. Societies face social change for a variety of reasons, including demographic shifts, economic growth or decline and political and cultural developments. Being concerned with facilitating 
social progress, social workers around the world have to deal with the social change that occurs in the societies in which they are engaged.

Tønnessen's article, 'Human development, inequality and social risks in Latin America and the Nordic countries' offers a bird's-eye view of the current situation in the two regions, drawing on data from the United Nations Development Programme (UNDP), the Organization for Economic Cooperation and Development (OECD) and the World Inequality Database. His investigation reveals systematic differences between Latin America and the Nordic region, and the achievement of considerable progress with regard to welfare levels in practically all Latin American countries. However, all of the five Nordic countries are considered as more highly developed by the UNDP in terms of human development, and even the most equal of the Latin American countries are significantly more unequal than any of the Nordic countries. Tønnessen concludes that inequality may very well be the most important challenge facing welfare development in Latin America. Despite this, some of the long-term concerns people have with regard to social and economic risks appear to be quite similar across the two regions, particularly with regard to our concern for economic security in old age.

Heitmann's contribution examines the Brazilian context for social work. While recognizing that Brazil and much of the Latin American continent has a historical legacy of exploitation and inequality, Heitmann stresses the need to acknowledge the limits of a strictly egalitarian understanding of citizenship. Social inclusion ultimately rests on personal relations, and in Heitmann's view, these should be seen as enabling rather than preventing social progress. As he stresses, because of a lack of satisfactory public structures and services in a Latin American context, informal personal relations have traditionally permeated many Latin American societies. This is also some of the background for the stronger emphasis on the responsibility of the family in Latin America. As a consequence, social workers in Brazil and other Latin American countries must be sensitive towards their relational contexts, and how their fight for universal rights affects the social circumstances of vulnerable groups. Informal approaches, such as the Brazilian 'jeitinho' (i.e. pragmatically 'finding a way' to resolve issues, whether inside or outside the law) may sometimes be reconcilable with social justice, but raises difficult ethical questions about fairness and equality. 


\section{Social work practice is context and welfare regime dependent}

The perceptions of front-line social worker professionals are important, as they are the street level implementers of national and global social work policies (Lipsky, 2010). The implementation of the United Nations Convention on the Rights of the Child (1989) is typical here, important for social workers as they adapt this to their national child protection and family/child welfare contexts. Social work is contextually dependant, with differing welfare regimes or regional differences having a significant impact on the practice of this profession (Healy \& Oltedal, 2010). Through comparing similarities and differences across social work practices in different contexts, the discipline is better understood.

Welfare regimes may be classified in numerous ways, e.g., social democratic, liberal and conservative systems (Esping-Andersen, 1990), or alternatively familiarized versus non-familiarized systems. In the latter, the balance between the responsibilities of family, state, market and civil society for the welfare of the individual and family unit are considered (Hantrais, 2004). Defamiliarized regimes emphasize the intervention of the state, while familiarized regimes favour noninterventionist approaches and a reliance on strong family relationships.

Judging by the articles of this special issue, Chile is an example of a familiarized welfare system embedded in a national context, characterized by medium inequalities in a Latin American context, as well as a high GDP compared to other countries in the region (see Jensen et al., Ellingsen et al. and Tønnessen, this volume). Whereas Chilean GDP per capita is less than half of the Nordic average, relatively high income in terms of GDP contributes to Chile's current ranking as the most developed Latin American country according to the United Nations Development Programme (UNDP 2018, see also Tønnessen). However, though both Brazil and Mexico are regarded as economic powerhouses on the global stage, that does not translate into an impressive performance with regard to Human Development, as both countries are held back by persistent inequality and ravaged by the insecurity that comes with epidemic levels of violence (see UNDP 2018 and Tønnessen, this volume). 
Cuba is an example of a familiarized welfare system existing within a country with a somewhat lower GDP (and lack of official data on inequality). In Cuba, social policies have tended to favour universalism and social solidarity, although the individual is today more reliant on the contribution of family or other social networks, and on informal income. This is the result of the state lacking the resources to fully satisfy the social needs of its citizens, thus forcing families to assume full or partial responsibility for services traditionally granted by the state. The situation has been formalized in recent social policy changes that promote the greater responsibility of the family (Peña, 2017). Studies on conditions in Norway offer insight into how defamiliarized welfare systems working within low inequalities and high GDP states may function. Oltedal et al. explore social work practices in the defamilialized Norway and the familialized Cuba. They find that Cuban social workers emphasize the family`s role in resolving cases, and that there is a cultural element related to the role of the family. In Norway, the welfare state has more resources at its disposal, but here social workers refer instead to difficulties in coordination between services. Whereas individual professionals are held to account in Cuba, institutions are held accountable in Norway.

\section{Discussion points}

We introduced this editorial by identifying a lack of research into social worker perspectives in a Latin American context, and calling for a comparison of these with European social work practices, particularly those in the Nordic region. This is a task that is only begun in this special issue. Work remains to be done on countries in the two regions beyond those covered in this issue, and from supplementary theoretical and methodological angles. Even though our experience is that making these comparisons can be fruitful, researchers should not forget that in some cases national or local characteristics may outweigh continental ones.

When doing international comparisons, there is a temptation to merge the global North and the South into two discrete groups, and perhaps assume that they have more in common than they have in reality. Is it useful to see Latin America as part of the global South and the Nordic countries as part of the global North? Relatedly, are terms such as 'developed' and 'developing' countries still useful, or are they outdated, as Tønnessen (this issue) suggests? 
In this special issue, contributors have predominantly investigated a social worker perspective, which at times is applied to matters related to childhood and family life. It would be advantageous if some of the future work to be done would aim to take the perspective of the children themselves (cf. Sommer et al., 2010).

One could also inquire more deeply into the question of to what extent welfare regimes determine the opportunity space for social work practices. In Brazil and Chile, respectively, Heitmann and Oltedal et al. describe the presence of strong and informal social relationships that are shaping and influencing social work practices. Bearing in mind a reciprocal relationship between structure and personal agency, questions such as these arise: Have cultures characterized by strong social and family relations developed welfare policies that formalize the responsibility of the family? Or is it rather the economic conditions of the country that has made an emphasis on family responsibility a necessity? In other words, to what extent are welfare policies shaped by cultural/normative and economic factors, respectively?

\section{References}

Esping-Andersen, G. (1990). The three worlds of welfare capitalism. Princeton, New Jersey: Princeton University Press.

Hantrais, L. (2004). Family policy matters. Responding to family change in Europe. Bristol: Policy Press. https://doi.org/10.2307/j.ctt1t893wm

Healy, K. (2014). Social Work Theories in Context: Creating Frameworks for Practice. London: Palgrave. https://doi.org/10.1007/978-1-137-02425-1

Healy, K., \& Oltedal, S. (2010). An institutional Analysis of Child Protection Workforce Turnover. An Australian and Norwegian Comparison. Journal of Social Policy 39(2), 255-274. https://doi.org/10.1017/S004727940999047X

Lipsky, M. (2010). Street-level Bureaucracy: Dilemmas of the Individual in Public Service. New York: Russell Sage Foundation.

Lyngstad, R. (2015). Different welfare system - same values? How social work educators in Norway, Chile and Argentina comprehend core social work and social policy issues. Social Sciences, 4(1), 239-259. https://doi.org/10.3390/socsci4010239 
Maclure, R. (2014). Introduction: Children's Rights in Latin America: Constraints and Possibilities. The International Journal of Children's Rights, 22(2), 235-239. https://doi.org/10.1163/15718182-02202007

Peña, A. (2017). Regímenes de bienestar y pobreza familiar en Cuba [Welfare regimes and family poverty in Cuba]. La Habana: Editorial Nuevo MilenioCiencias Sociales.

Sommer, D., Samuelsson, I. P., \& Hundeide, K. (2010). Child perspectives and children's perspectives in theory and practice (vol. 2). New York: Springer Science \& Business Media. https://doi.org/10.1007/978-90-481-3316-1

United Nations Convention on the Rights of the Child (1989). Available at http://www.ohchr.org/en/professionalinterest/pages/crc.aspx. [Accessed on 28 January 2016.]

UNDP (2018). Human Development Indices and Indicators - 2018 Statistical Update. New York: United Nations Development Programme. 